\title{
The Use of Laser Therapy for Patients with Fibromyalgia: A Critical Literary Review
}

\author{
Serguei Borisovich Kisselev ${ }^{1}$, Sergey Vladimirovich Moskvin ${ }^{2 *}$ \\ 'Advanced Rural Health, KRISS, LASMIK Australia, FRACGP, the Australian Association of Musculoskeletal Medicine \\ (AAMM), Taringa, Australia \\ ${ }^{2}$ The Federal State-Financed Institution "O.K. Skobelkin State Scientific Center of Laser Medicine under the Federal Medical \\ Biological Agency", Moscow, Russia
}

\author{
*Correspondence to \\ Sergey Vladimirovich Moskvin \\ Doctor of Biological Sciences, \\ Candidate of Technical Sciences, \\ Leading Researcher of The Federal \\ State-Financed Institution "O.K. \\ Skobelkin State Scientific Center of \\ Laser Medicine under the Federal \\ Medical Biological Agency", address: \\ Studencheskaya ul., 40, Moscow, \\ Russia, 121165 \\ Tel: +7(905)770-18-60; \\ Email:7652612@mail.ru
}

Published online 15 December 2018

\begin{abstract}
The management of pain - despite many anaesthetic drugs - remains to be an urgent task. If the goal is to achieve permanent pain relief - and not to temporarily mask the pain (masking pathology) - then this goal can only be achieved by treating pain with physiotherapeutic methods, the most universal and effective of which, is low level laser therapy (LLLT).

The treatment methods vary fundamentally in the case of neuropathic (nonspecific, primary) pain, which includes pain with the localization of the trigger points (TP) and nociceptive (specific, secondary), which includes all types of pain resulting from trauma, inflammation, etc. When treating patients with fibromyalgia (FM), a comprehensive approach is required, using different methods of laser therapy and guided by well-known rules. These rules include setting all the correct parameters of the laser exposure (wavelength, operating mode, power, exposure, etc), limiting exposure and power to optimal values and limiting the total time of the procedure and the number of procedures per course.

Keywords: Pain; Fibromyalgia; Low level laser therapy.
\end{abstract}

\section{Introduction}

Pain is a concept that is clinically and pathogenetically complex and heterogeneous. It differs in intensity, localization and subjective manifestations (shooting, pressing, pulsating, pricking, cutting, whining, etc) and can be permanent or periodic. All the existing varieties of the characteristics of pain are largely related to localization and what caused it. For pain management, an educated choice is made when administered appropriate medicines and effective treatment methods, particularly like laser therapy. To make these choices, it is essentially important to distinguish the two variants based on pathophysiological mechanisms: neuropathic (nonspecific, primary) and nociceptive (specific, secondary) pain. ${ }^{1,2}$

A striking example of the widespread muscle or jointmuscle pain is fibromyalgia (FM) - rheumatic disease of unclear etiology, characterized by generalized muscle weakness (a fatigue sensation) and painful palpations of characteristic areas of the body, considered to be tender points by some authors, ${ }^{3}$ and trigger points by others. ${ }^{4}$

According to studies about FM, around 6 million Americans suffer from it, while 4 million of them are women. Although there is no distinct pathophysiological basis of the disease, such patients are easily recognized by the characteristic prevalence and localization of pain in their bodies. Over long periods of observation, specialists came to the unequivocal conclusion that the treatment of patients with FM should be individual, and requires a holistic approach; they need time, empathy, and interaction with other professionals. Ensuring the effective management of these patients is often a real test of the professionalism of the physician. ${ }^{5}$

It is necessary to discuss some of the words and terms used, which are extremely important in our case. Initially, the term tender points was used for $\mathrm{FM}^{6}{ }^{6}$ and trigger points for myofascial pain syndrome (MPS), ${ }^{7}$ all the while emphasizing the differences in the pathogenesis of the diseases themselves and the differences in the local painful areas. ${ }^{8,9}$ In recent years, however, the situation has changed, and most experts tend to the fact that the "points" defined by the Moscow International AIDS Foundation are virtually impossible to distinguish clinically or pathophysiologically from those characteristic of FM, and the disease itself represents the stages of a single process of chronic muscle pain. ${ }^{10}$ Therefore, it is logical to combine two variants of definition of points and call them "TP", especially since the initial letters of word combinations are identical. 
But the most important thing is that the TP's (tender points or trigger points) are the result of the nonspecific response of the central nervous system (CNS) in its interaction with the autonomic nervous system (ANS), which manifests itself in both FM and MPS. That is, the pain occurs in TP is neuropathic (nonspecific, primary), and explains the recommended integrated approach to solve the problem of the management of the pain syndrome in FM.

Sometimes, quite typically $\mathrm{TP}$ is confused with any local painful zone (PZ), when the pain induced by a pathological process (trauma, inflammation, etc), and has a nociceptive nature. Pathophysiological differences in the causes of 2 types of pain warrant two different types of approaches for its elimination. On the other hand, it is quite difficult to distinguish them, since there are no reliable objective methods of differentiation. Therefore, creates additional difficulties in the correct interpretation and systematization of scientific data.

Despite a significant number of drug and nonpharmacological methods of treatment for patients with FM, their effectiveness is not good enough. In addition, long-term use of analgesics, sedatives and non-steroidal anti-inflammatory drugs (NSAIDs) - commonly used for treatment - lead to the development of side effects, the aggravation and the severity of the patients' condition. ${ }^{11}$ Low-level laser therapy (LLLT) is the most universal therapeutic factor, which has no side effects or absolute contraindications, while unlike analgesics, it does not target only one link in the painful reception, but targets essentially the whole hierarchy of mechanisms of its origin and regulation. ${ }^{9}$

The use of the integrated approach, which involves a wide range of LLLT methods, allows restoring any abnormalities in the functioning of various organs and systems of the human body, which, in addition to directly blocking pain, ensures the elimination of the causes of the disease. This "universality" predetermines the exceptional effectiveness of LLLT in the reliable elimination of pain syndromes of different types, provided by varying the parameters of the techniques. Equally importantly, after a well-organized and methodized course of laser therapy, the healing effect persists for long periods of time, i.e. months and years. It is even possible to talk about this treatment in such a way that suggests the patient will forget out their pain, if not forever, then for a very long time., ${ }^{2,9}$

In this article, we are not looking at the "analgesic" mechanisms of biomodulatory action (BA) of lowintensity laser illumination (LLLI), however, a lot of work is devoted to this topic, we recommend you to read the latest published works on this issue. ${ }^{12,13}$ But it is necessary to note the fact that practically none of the works deal with "laser pain management", considering one important circumstance - what type of pain, primary or secondary, i.e. they do not show the differences in the reasons of its occurrence when choosing the laser exposure technique. This is fundamentally important in this case. The methods of laser therapy are quite simple and absolutely safe. This follows directly from the known mechanisms of the LILI database, the illumination that causes the body's response through the initiation of $\mathrm{Ca}^{2+}$-dependent processes at a cellular level, after which the disturbed homeostasis is restored through the development of the secondary response of various regulatory systems and organs, resulting in the patient's recovery. ${ }^{14-16}$

However, it is necessary to understand that the safety and effectiveness of any method of treatment, including laser therapy, is achieved only if it is applied correctly. There are several common methods of laser therapy (methods of laser illumination). ${ }^{9,16}$

- external illumination;

- projection of the internal organs;

- on immunocompetent organs;

- on large blood vessels: intravenous laser blood illumination (ILBI) and non-invasive laser blood illumination (NLBI);

- paravertebral;

- $\quad$ at the acupuncture points (AP);

- $\quad$ at trigger points (TP), painful points (PP) and painful areas (PA).

There are some very strict rules for the use of these techniques $^{17}$ :

- limiting of the exposure time,

- determination and use of the optimal power density (PD) and the wavelength of LLLT,

- preferred use of pulse mode, which is especially important for pain management, etc.

Unfortunately, in most works which use laser therapy as the main method of treatment for patients with FM and other pain syndromes, the parameters of the method are far from effective, so often the results are not impressive. The purpose of the review is to analyze various methodologies and methodological errors made by many researchers, and to develop recommendations based on the available scientific data, and to develop a correct understanding of the mechanisms of the LILI database and its own clinical experience.

We compiled a table with the most accurate indication of all parameters of the method of treatment of patients with FM, and in some pain syndromes, paying attention to those works in which the result was not obtained, while using the same parameters of the procedure (Table 1). We have maintained the authentic terminology in terms of diseases (FM and MPS).

Unlike other reviews, which mainly focus on the reliability of the obtained results (which is extremely important), the errors are analyzed below, and the pros and cons of each are listed, also it is suggested to more independently understand the various methods of influence.

Uncertainty in relation to TP (trigger points, tender points) and generally PZs, clear and unambiguous division of them, often leads to mistakes in the choice of tactics of treatment and methodology. In many works these 


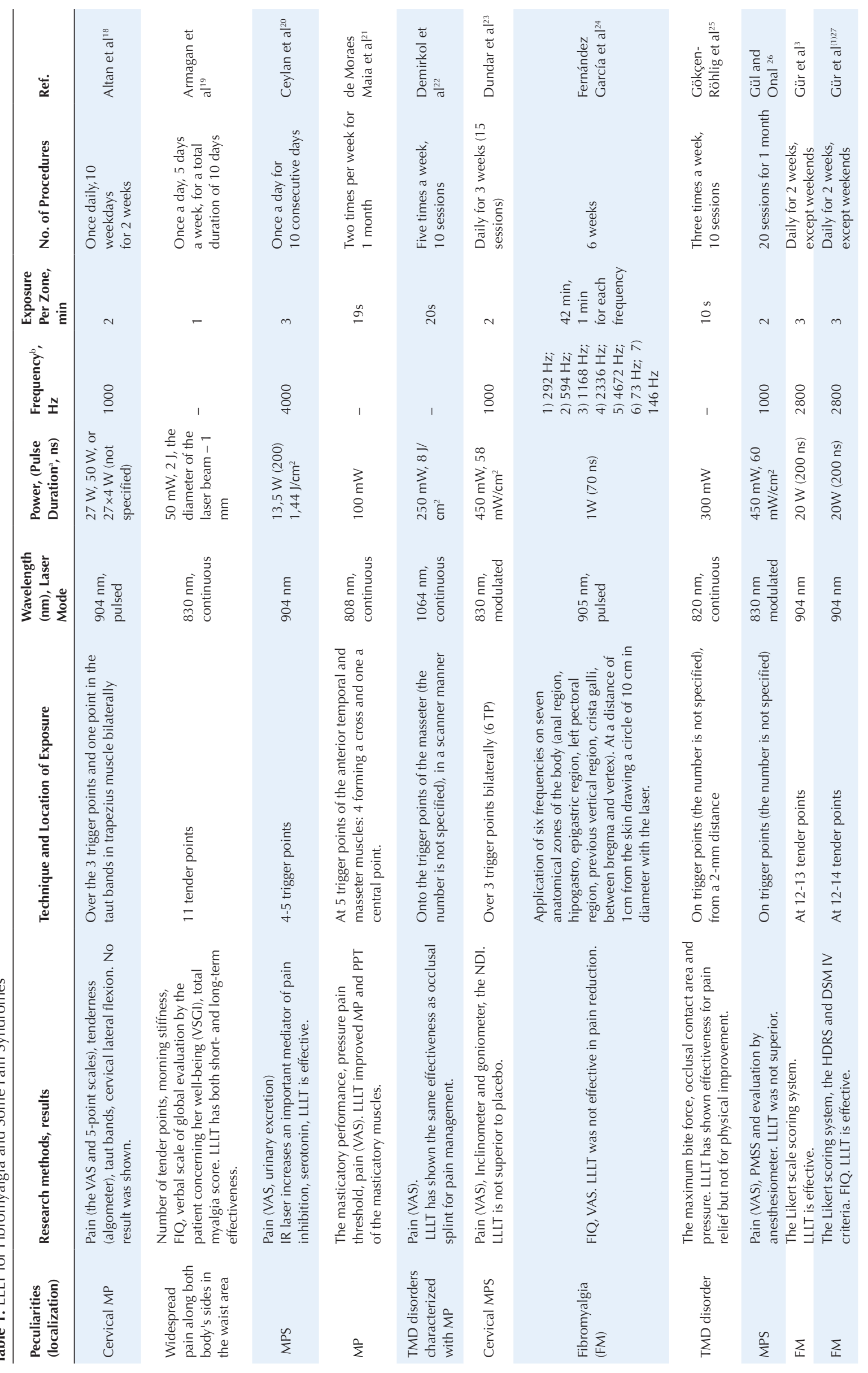




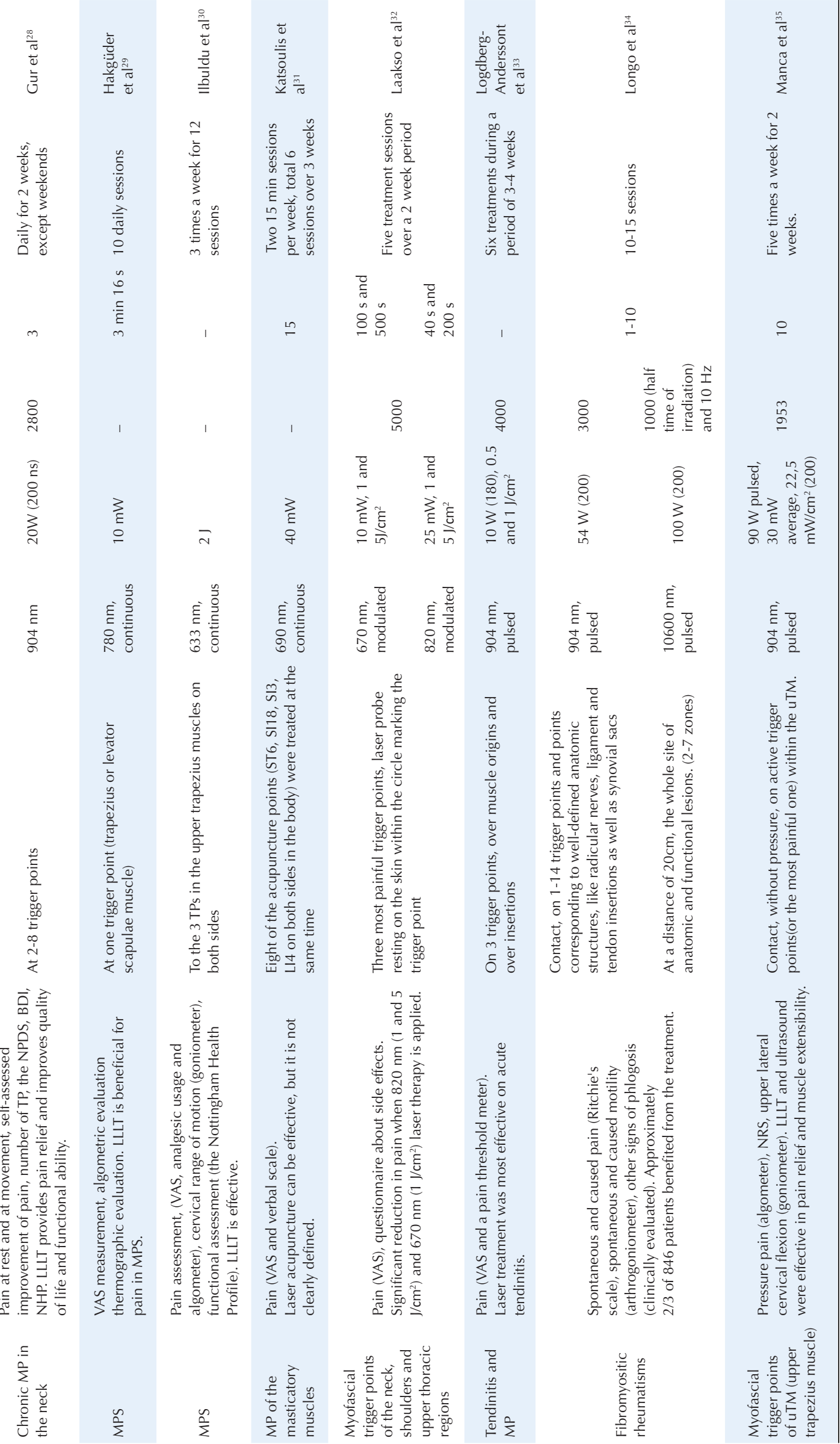




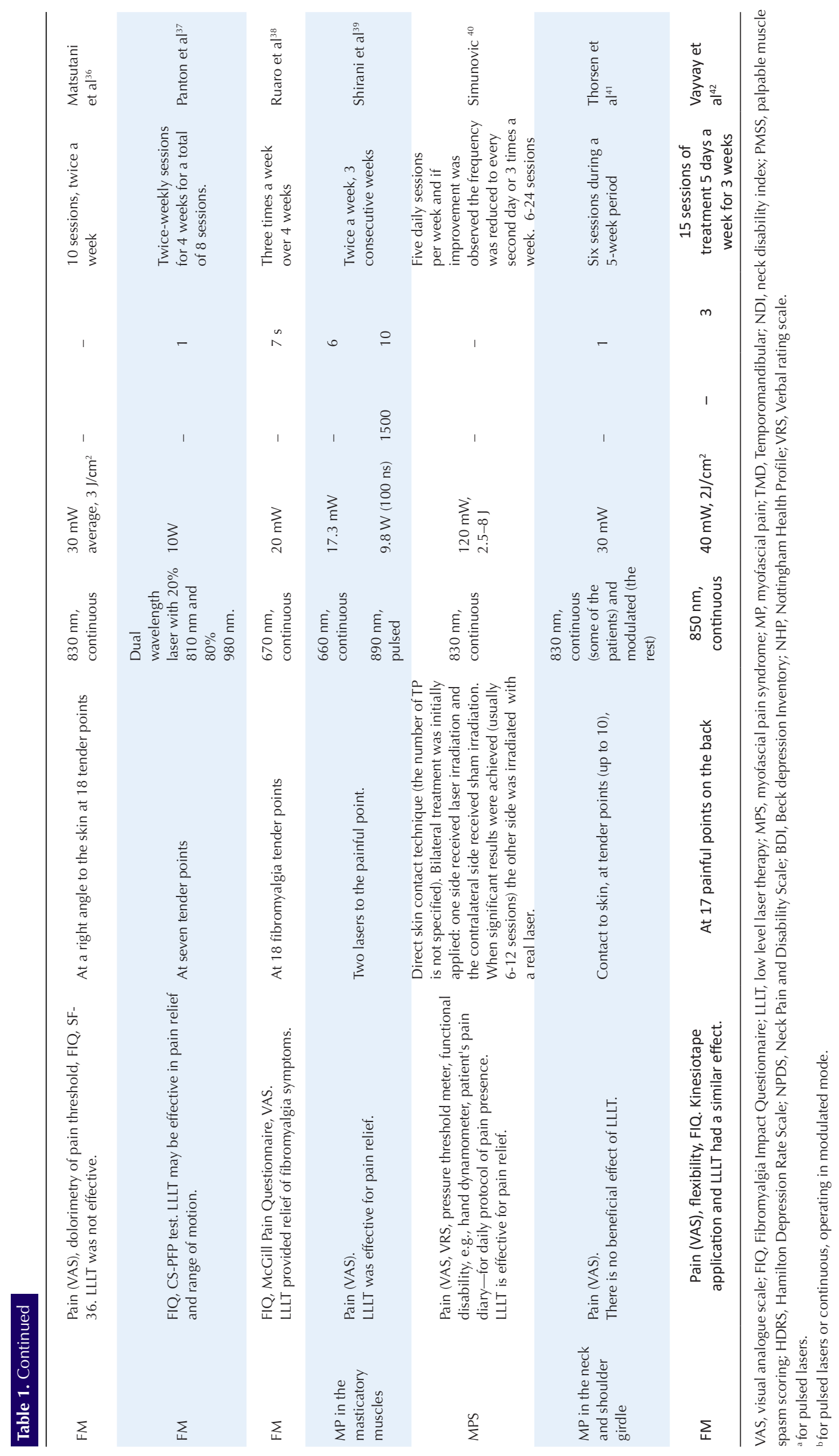


concepts are confused (Table 1). The lack of uniformity and a "standard" of terminology hinder the development of the methodology of treatment of patients with FM. The table does not include the only experiment in which it was shown that the laser illumination of New Zealand rabbits (contact for 5 myofascial TP and muscle tension zones, $780 \mathrm{~nm}$, continuous mode, $30 \mathrm{~mW}, 30$ seconds $\left(4.5 \mathrm{~J} / \mathrm{cm}^{2}\right)$ or 3 minutes $\left(27 \mathrm{~J} / \mathrm{cm}^{2}, 5\right.$ consecutive days) affects some biochemical indicators associated with pain ( $\beta$-endorphin, substance $\mathrm{P}$, tumor necrosis factor TNF- $\alpha$ and cyclooxygenase-2). The conclusion is that the results depend on the energy density (ED), different biochemical parameters vary to different degrees with an increasing or decreasing ED. ${ }^{43}$

However, in this work, one important fact was neglected, specifically, that the change in the ED was due to arithmetic actions $\left(\mathrm{J} / \mathrm{cm}^{2}\right)$ - in the case of exposure variation nonlinearly affects the result (the effect), it is permissible to change only the power and area of influence of essential restrictions. In other words, with formally identical values of ED derived from different exposures, the effect can differ by mirror-image, and both the stimulation and inhibition of some process occur. This is one of the most common mistakes.

A majority of specialists only use the method of illuminating TP's with lasers, which is not always effective. Indeed, it has been shown for a long time that the illumination of TP by a continuous LLLT of the red spectrum $(633 \mathrm{~nm})$ causes changes in sympathetic activity, accompanied by an increase of skin resistance at the site of exposure. ${ }^{44,45}$ The latency of peripheral sensory nerve fibers increases, which leads to a decline in the conduction velocity of the nerve impulse, and ultimately, to a decrease in pain ${ }^{46}$ But this is not enough.

In some studies, the role of metabolic shifts in the etiopathogenesis of FM, particularly energy processes are discussed. This aspect is considered from the position of the analysis of the mechanism of the onset of TP, for example, in tissue biopsies taken from these points, a decrease in the content of high-energy phosphates was detected $^{47,48}$ as well as a change in phosphodiesterase activity. ${ }^{49}$ Data from the spectrographic study of muscles are evidence of local hypoxia. ${ }^{50} \mathrm{~A}$ study by Bochkova ${ }^{11}$ showed that after the course of illumination therapy, with the presence of NSAIDs and antidepressants, $82 \%$ of patients had a normalization of the isoenzymatic spectrum of lactate dehydrogenase occur, which contributes to the improvement of energy supply to muscle tissue, the number of TP decreased and the morbidity of the surviving tissues reduced. This is a very important conclusion, objectively confirming the influence of LLLT on TP.

However, in addition to the pain syndrome typical for FM, a complex treatment with several RT methods is required, analysis of studies and independent clinical experience allows us to conclude that the effect of continuous LILI on TP is ineffective, it is necessary to use the pulsed mode and the infrared (IR) spectrum (duration of the light pulse 100-150 ns, pulsed power 10-15 W, wavelength 904 $\mathrm{nm}){ }^{11,51}$

If you analyse the publications on the topic, including those listed in Table 1, it can be seen that in the vast majority of cases, laser light is used in a continuous mode. In some cases, when using this option, one can get some effects, but it is not very pronounced, not prolonged and not always reliable, even though in Table 1 it shows that it is given positive results. Attempts to increase efficiency by increasing the power of laser light do not always help. 23,25 It is known that when the frequency of pulsed lasers varies, the average power proportionally varies, which is actively used to vary the ED and allows optimizing the laser action. For different techniques, different frequencies (read, power) are optimal, but we repeat that this is true only for e LLLI-impulse. The work of Altan et $\mathrm{al}^{18}$ shows evidence in which the same modes are used for TP and also PZ, which are not related to the TP, and in both cases the frequency of $1000 \mathrm{~Hz}$ is not optimal. It would be correct to use LLLT with a varying frequency on TP, starting from $80 \mathrm{~Hz}$ (see below), when lighting the PZ, using frequencies above $3000 \mathrm{~Hz}$ for the first 1-2 sessions, then reducing to $80 \mathrm{~Hz}$.

As we noted above, in the case of FM, the pain syndrome has its own peculiarities, which is the reason for using only complex laser therapy techniques, when various methods of action directed at different pathogenetic links are involved. One of the examples of the complex approach can be a technique in which the laser action of pulsed IR LLLT $(890 \mathrm{~nm})$ is performed in a transcranial manner on the TP and acupuncture points, and the pulse repetition rate is varied, which is extremely important in this case. ${ }^{51}$

In the following, a little more about the frequencies for pulsed lasers are discussed. The first to suggest to vary the frequencies of pulsed infrared lasers was Liev et $\mathrm{al},{ }^{52}$ the essence of the technique is a gradual increase in the frequency from $80 \mathrm{~Hz}$ in the first procedure, to $3000 \mathrm{~Hz}$ in the 7 th-8th procedures, then gradually reducing to $80 \mathrm{~Hz}$ by the 15th-16th procedures. Later, this technique was improved, and the limiting frequency was increased to $10000 \mathrm{~Hz}$ (this makes it possible to use the laser therapeutic apparatus "LASMIK").9,15 The logic of this approach is quite understandable to anyone who knows the basics of neurophysiology of pain and the mechanisms of LLLT. But the parameters of exposure to specific PZ's, directly related to the focus of pathology, are fundamentally different, and not always unambiguous. In the management of pain, exposure is extremely important. Most Russian authors recommend exposures from 20 to 60 seconds per one TP, for one procedure no more than 10-12 points, for a course of at least $12-16$ procedures. ${ }^{11,51}$ In Table. 1 we see a rather wide range of exposures used in various studies, which is not always justified. When 
exposed to specific PZ's, exposure is optimal at 5 minutes per zone, possibly even two mins in case of multiple localization or additional use of other laser therapy methods during the procedure.

Since the total time of the procedure cannot exceed 20 minutes, ${ }^{17}$ this replacement (5 minutes instead of two minutes) is justified. The use of other exposures is not allowed in most cases (there are some exceptions). Violation of the rule "the procedure of laser therapy should not last more than 20 minutes" is the reason for the lack of results in a number of studies. ${ }^{24,42}$ In the management of pain, this is especially critical, since the maximum response of the CNS and ANS, including the nociceptive system, occurs exactly 20 minutes from the start of the procedure.

In one of the works (not included in Table 1), with the reference to Russian studies, the possibility of using VLOK-635 (wavelength 633-635 nm, power of 1-2 $\mathrm{mW}$ ) is justified for the treatment of patients with fibromyalgia. ${ }^{53}$ The authors motivate their choice by such well-known results of laser illumination as a normalization of the immune system, improvement of the rheological properties of blood and trophic provision of tissues.

Improvement of microcirculation and oxygen supply of various tissues after VLOK-635 is also closely related to the positive influence of LILI on the metabolism: the oxidation of energy materials - glucose, pyruvate, lactate - elevates. ${ }^{54}$ However, quite often (and very successfully) the intravenous version of the laser blood-clarification technique is replaced by a non-invasive (transcutaneous) method, using matrix red pulsed lasers (wavelength 635 $\mathrm{nm}$, pulse power $40 \mathrm{~W}$ with eight pieces of laser diodes arranged as four in 2 rows, an area of $8 \mathrm{~cm}^{2}$, a pulse duration of $100-150 \mathrm{~ns}$, a frequency of $80-150 \mathrm{~Hz}$ ). ${ }^{2,55}$ Thus, we can draw the following conclusions:

1. Methods of pain management are fundamentally different for neuropathic pain (nonspecific, primary), which includes pain with localization in TP, and nociceptive pain (specific, secondary), which includes all types of pain arising from trauma, inflammation, etc.

2. In the treatment of patients with FM, it is necessary to use only complex treatment, including the use of various methods of laser therapy.

3 . It is necessary to be guided by some rules for carrying out laser therapy, in particular, to set all parameters of laser exposure (wavelength, operating mode, power, exposure, etc), limit exposure and power to optimal values, limit the total time of the procedure and the number of procedures per course.

\section{Ethical Considerations}

Not applicable.

\section{Conflict of Interests}

The authors declare no conflict of interest.

\section{References}

1. Veyn AM, Voznesenskaya TG, Danilov AB, et al. Pain syndromes in neurological practice (Russian). Moscow: MED press; 1999.

2. Kochetkov AV, Moskvin SV, Karneev AN. Laser Therapy in Neurology (Russian). Moscow-Tver: Triada; 2012.

3. Gur A, Karakoc M, Nas K, Cevik R, Sarac J, Demir E. Efficacy of low power laser therapy in fibromyalgia: a single-blind, placebo-controlled trial. Lasers Med Sci. 2002;17(1):57-61. doi:10.1007/s101030200010

4. Ge HY, Wang Y, Fernandez-de-las-Penas C, GravenNielsen T, Danneskiold-Samsoe B, Arendt-Nielsen L. Reproduction of overall spontaneous pain pattern by manual stimulation of active myofascial trigger points in fibromyalgia patients. Arthritis Res Ther. 2011;13(2):R48. doi:10.1186/ar3289

5. Bennett R. Fibromyalgia: Shining a light on fibromyalgia treatment. Nat Rev Rheumatol. 2016;12(10):568-569. doi:10.1038/nrrheum.2016.149

6. Freundlich B, Leventhal LJ. Comment on the 1990 American College of rheumatology criteria for fibromyalgia. Arthritis Rheum. 1990;33(12):1863-1864.

7. Travell JG, Simons DG. Myofascial Pain and Dysfunction: The Trigger Point Manual. Baltimore, MD: Williams \& Wilkins; 1983:59-63.

8. Bennett RM, Goldenberg DL. Fibromyalgia, myofascial pain, tender points and trigger points: splitting or lumping? Arthritis Res Ther. 2011;13(3):117. doi:10.1186/ar3357

9. Moskvin SV. Basics of laser therapy (Russian). MoscowTver: Triada; 2016. Series Effective Laser Therapy. vol 1.

10. Malykhin MY, Vasilenko AM. Are myofascial pain syndrome and fibromyalgia different diseases, or are they the stages of a single pathological process? [Russian] http:// www.painstudy.ru/matls/review/mbs.htm. Published 2017.

11. Bochkova IA. Clinical-enzymological assessment of the effectiveness of laser therapy in primary fibromyalgia syndrome [ thesis]. [Russian]. Volgograd; 1998.

12. Chow R, Armati P, Laakso EL, Bjordal JM, Baxter GD. Inhibitory effects of laser irradiation on peripheral mammalian nerves and relevance to analgesic effects: a systematic review. Photomed Laser Surg. 2011;29(6):365381. doi:10.1089/pho.2010.2928

13. Chow RT, Armati PJ. Photobiomodulation: implications for anesthesia and pain relief. Photomed Laser Surg. 2016;34(12):599-609. doi:10.1089/pho.2015.4048

14. Moskvin SV. On the problem of the mechanisms of the therapeutic effect of the low-intensity laser irradiation (LILI) (Russian). Bulletin of New Medical Technologies. 2008;15(1):167-172.

15. Moskvin SV. The effectiveness of laser therapy (Russian). Moscow-Tver: Triada; 2014. Series Effective laser therapy. vol 2 .

16. Moskvin SV. Low-level laser therapy in Russia: history, science and practice. J Lasers Med Sci. 2017;8(2):56-65. doi:10.15171/jlms.2017.11

17. Gerasimenko MY, Geynits AV, Moskvin SV, et al. Laser therapy in medical rehabilitation and prevention programs (Russian). Moscow: Clinical Guidelines; 2015.

18. Altan L, Bingol U, Aykac M, Yurtkuran M. Investigation of 
the effect of GaAs laser therapy on cervical myofascial pain syndrome. Rheumatol Int. 2005;25(1):23-27. doi:10.1007/ s00296-003-0396-y

19. Armagan O, Tascioglu F, Ekim A, Oner C. Long-term efficacy of low level laser therapy in women with fibromyalgia: A placebo-controlled study. J Back Musculoskelet Rehabil. 2006;19(4):135-140. doi:10.3233/BMR-2006-19405

20. Ceylan Y, Hizmetli S, Silig Y. The effects of infrared laser and medical treatments on pain and serotonin degradation products in patients with myofascial pain syndrome. A controlled trial. Rheumatol Int. 2004;24(5):260-263. doi:10.1007/s00296-003-0348-6

21. de Moraes Maia ML, Ribeiro MA, Maia LG, et al. Evaluation of low-level laser therapy effectiveness on the pain and masticatory performance of patients with myofascial pain. Lasers Med Sci. 2014;29(1):29-35. doi:10.1007/s10103-0121228-7

22. Demirkol N, Sari F, Bulbul M, Demirkol M, Simsek I, Usumez A. Effectiveness of occlusal splints and lowlevel laser therapy on myofascial pain. Lasers Med Sci. 2015;30(3):1007-1012. doi:10.1007/s10103-014-1522-7

23. Dundar U, Evcik D, Samli F, Pusak H, Kavuncu V. The effect of gallium arsenide aluminum laser therapy in the management of cervical myofascial pain syndrome: a double blind, placebo-controlled study. Clin Rheumatol. 2007;26(6):930-934. doi:10.1007/s10067-006-0438-4

24. Fernandez Garcia R, Suarez Holgado JD, Formieles Ortiz I, Zurita Ortega F, Valverde Cepeda M, Fernandez Sanchez M. Using a laser based program in patients diagnosed with fibromyalgia. Reumatol Clin. 2011;7(2):94-97. doi:10.1016/j.reuma.2010.01.007

25. Gokcen-Rohlig B, Kipirdi S, Baca E, Keskin H, Sato S. Evaluation of orofacial function in temporomandibular disorder patients after low-level laser therapy. Acta Odontol Scand. 2013;71(5):1112-1117. doi:10.3109/00016357.2012. 749517

26. Gul K, Onal SA. Comparison of non-invasive and invasive techniques in the treatment of patients with myofascial pain syndrome. Agri. 2009;21(3):104-112.

27. Gur A, Karakoc M, Nas K, Cevik R, Sarac J, Ataoglu S. Effects of low power laser and low dose amitriptyline therapy on clinical symptoms and quality of life in fibromyalgia: a single-blind, placebo-controlled trial. Rheumatol Int. 2002;22(5):188-193. doi:10.1007/s00296-002-0221-z

28. Gur A, Sarac AJ, Cevik R, Altindag O, Sarac S. Efficacy of $904 \mathrm{~nm}$ gallium arsenide low level laser therapy in the management of chronic myofascial pain in the neck: a double-blind and randomize-controlled trial. Lasers Surg Med. 2004;35(3):229-235. doi:10.1002/lsm.20082

29. Hakguder A, Birtane M, Gurcan S, Kokino S, Turan FN. Efficacy of low level laser therapy in myofascial pain syndrome: an algometric and thermographic evaluation. Lasers Surg Med. 2003;33(5):339-343. doi:10.1002/ lsm. 10241

30. Ilbuldu E, Cakmak A, Disci R, Aydin R. Comparison of laser, dry needling, and placebo laser treatments in myofascial pain syndrome. Photomed Laser Surg. 2004;22(4):306-311. doi:10.1089/pho.2004.22.306

31. Katsoulis J, Ausfeld-Hafter B, Windecker-Getaz I, Katsoulis K, Blagojevic N, Mericske-Stern R. Laser acupuncture for myofascial pain of the masticatory muscles. A controlled pilot study. Schweiz Monatsschr Zahnmed. 2010;120(3):213225.

32. Laakso EL, Richardson C, Cramond T. Pain scores and side effects of low level laser therapy in the treatment of myofascial trigger points. Laser Ther. 1997;9(2):67-72. doi:10.5978/islsm.9.67

33. Logdberg-Anderssont M, Mutzell S, Hazel A. Low level laser therapy (LLLT) Of tendinitis and myofascial pains a randomized, double-blind, controlled study. Laser Ther. 1997;9(2):79-85. doi:10.5978/islsm.9.79

34. Longo L, Simunovic Z, Postiglione M, Postiglione M. Laser therapy for fibromyositic rheumatisms. J Clin Laser Med Surg. 1997;15(5):217-220. doi:10.1089/clm.1997.15.217

35. Manca A, Limonta E, Pilurzi G, et al. Ultrasound and laser as stand-alone therapies for myofascial trigger points: a randomized, double-blind, placebo-controlled study. Physiother Res Int. 2014;19(3):166-175. doi:10.1002/ pri. 1580

36. Matsutani LA, Marques AP, Ferreira EA, et al. Effectiveness of muscle stretching exercises with and without laser therapy at tender points for patients with fibromyalgia. Clin Exp Rheumatol. 2007;25(3):410-415.

37. Panton L, Simonavice E, Williams K, et al. Effects of Class IV laser therapy on fibromyalgia impact and function in women with fibromyalgia. J Altern Complement Med. 2013;19(5):445-452. doi:10.1089/acm.2011.0398

38. Ruaro JA, Frez AR, Ruaro MB, Nicolau RA. Low-level laser therapy to treat fibromyalgia. Lasers Med Sci. 2014;29(6):1815-1819. doi:10.1007/s10103-014-1566-8

39. Shirani AM, Gutknecht N, Taghizadeh M, Mir M. Low-level laser therapy and myofacial pain dysfunction syndrome: a randomized controlled clinical trial. Lasers Med Sci. 2009;24(5):715-720. doi:10.1007/s10103-008-0624-5

40. Simunovic Z. Low level laser therapy with trigger points technique: a clinical study on 243 patients. J Clin Laser Med Surg. 1996;14(4):163-167. doi:10.1089/clm.1996.14.163

41. Thorsen H, Gam AN, Svensson BH, et al. Low level laser therapy for myofascial pain in the neck and shoulder girdle. A double-blind, cross-over study. Scand J Rheumatol. 1992;21(3):139-141.

42. Vayvay ES, Tok D, Turgut E, Tunay VB. The effect of Laser and taping on pain, functional status and quality of life in patients with fibromyalgia syndrome: A placeborandomized controlled clinical trial. J Back Musculoskelet Rehabil. 2016;29(1):77-83. doi:10.3233/bmr-150600

43. Hsieh YL, Hong CZ, Chou LW, Yang SA, Yang CC. Fluencedependent effects of low-level laser therapy in myofascial trigger spots on modulation of biochemicals associated with pain in a rabbit model. Lasers Med Sci. 2015;30(1):209216. doi:10.1007/s10103-014-1654-9

44. Snyder-Mackler L, Bork C, Bourbon B, Trumbore D. Effect of helium-neon laser on musculoskeletal trigger points. Phys Ther. 1986;66(7):1087-1090.

45. Snyder-Mackler L, Barry AJ, Perkins AI, Soucek MD. Effects of helium-neon laser irradiation on skin resistance and pain in patients with trigger points in the neck or back. Phys Ther. 1989;69(5):336-341.

46. Snyder-Mackler L, Bork CE. Effect of helium-neon laser irradiation on peripheral sensory nerve latency. Phys Ther. 1988;68(2):223-225.

47. Bengtsson A, Henriksson KG, Larsson J. Reduced 
high-energy phosphate levels in the painful muscles of patients with primary fibromyalgia. Arthritis Rheum. 1986;29(7):817-821.

48. Henriksson KG, Bengtsson A. Muscular changes in fibromyalgia and their significance in diagnosis. Adv Pain Res Ther. 1990;17(3):259-267.

49. Jubrias SA, Bennett RM, Klug GA. Increased incidence of a resonance in the phosphodiester region of $31 \mathrm{P}$ nuclear magnetic resonance spectra in the skeletal muscle of fibromyalgia patients. Arthritis Rheum. 1994;37(6):801807.

50. Bengtsson A, Henriksson KG, Larsson J. Muscle biopsy in primary fibromyalgia. Light-microscopical and histochemical findings. Scand J Rheumatol. 1986;15(1):1-6.

51. Patent 2199357 RU. Int.Cl. A61N5/067. Method of treating of myofascial pain / AR Evstigneev, SV Karius. - №
2001122288/14; Date of filling 09.08.2001; Publ. 27.02.2003.

52. Liev AA, Apakidze TV, Kovalenko VV. Laser therapy of myofascial lumboschialgic syndromes [Russian]. Kislovodsk; 1996.

53. Momenzadeh S, Abbasi M, Ebadifar A, Aryani M, Bayrami J, Nematollahi F. The intravenous laser blood irradiation in chronic pain and fibromyalgia. J Lasers Med Sci. 2015;6(1):6-9. doi:10.22037/2010.v6i1.7800

54. Skupchenko VV. The Phasotonic brain [Russian]. Khabarovsk: Far Eastern Branch of the Academy of Sciences of the USSR; 1991.

55. Patent 2539535 RU, Int.Cl. A61N5/067. Matrix laser emitter for physiotherapeutic device / SV Moskvin. - № 2013137646/14. Date of filling: 12.08.2013. Publ. 20.01.2015. Bull. № 2. 